\title{
COVID-19 and Oral Diseases: How can we Manage Hospitalized and Quarantined Patients while Reducing Risks?
}

\author{
Pier Carmine Passarelli ${ }^{1}$, Giu seppe Passarelli ${ }^{2}$, Ioannis Alexandros Charitos ${ }^{3}$, Edoardo Rella ${ }^{4}$, Luigi Santacroce $5^{5^{*}}$, \\ Antonio D'Addona ${ }^{6}$
}

\begin{abstract}
${ }^{1}$ Master Coordinator, Department of Head and Neck and Sensory Organs, Division of Oral Surgery and Implantology, Fondazione Policlinico Universitario A. Gemelli IRCCS-Università Cattolica del Sacro Cuore, Rome, ITALY

${ }^{2}$ Private Practice, Castrovillari, ITALY

${ }^{3}$ Department of Emergency and Urgency, National Poisoning Centre, Riuniti University Hospital of Foggia, Foggia, ITALY

${ }^{4}$ Department of Head and Neck and Sensory Organs, Division of Oral Surgery and Implantology, Fondazione Policlinico Universitario A. Gemelli IRCCS-Università Cattolica del Sacro Cuore, Rome, ITALY

${ }^{5}$ Ionian Department, Microbiology and Virology Lab., Policlinico University Hospital of Bari, Bari, ITALY

${ }^{6}$ Professor and Head, Department of Head and Neck and Sensory Organs, Division of Oral Surgery and Implantology, Fondazione Policlinico Universitario A. Gemelli IRCCS-Università Cattolica del Sacro Cuore, Rome, ITALY

*Corresponding Author: luigi.santacroce@uniba.it
\end{abstract}

Citation: Passarelli PC, Passarelli G, Charitos IA, Rella E, Santacroce L, D’Addona A. COVID-19 and Oral Diseases: How can we Manage Hospitalized and Quarantined Patients while Reducing Risks?. Electron J Gen Med. 2020;17(6):em238. https://doi.org/10.29333/ejgm/7945

\begin{tabular}{|c|c|}
\hline ARTICLE INFO & ABSTRACT \\
\hline Received: 11 Apr. 2020 & w the importance of managing the oral health of patients with Coronavirus Disease 2019 (COVID-19) and \\
\hline Accepted: 12 Apr. 2020 & $\begin{array}{l}\text { the risk of acquire it in all healthcare workers. Dental pathologies are very frequent and there is a risk of facing } \\
\text { many dental emergencies in the following weeks and months. Therefore, here we propose some simple } \\
\text { procedures attempting to prevent them. }\end{array}$ \\
\hline
\end{tabular}

Keywords: Coronavirus, COVID-19, dental emergencies, risk management

\section{INTRODUCTION}

The novel Coronavirus, officially named as SARS-CoV-2 (Severe Acute Respiratory Syndrome Coronavirus 2), is a newly diagnosed virus, responsible for the so-called Coronavirus Disease 2019 (COVID-19), associated with a highly aggressive form of pneumonia (1).

This virus appears to be extremely contagious, even when compared to SARS, and the COVID-19 can be so severe that a high percentage of people may need invasive mechanic ventilation, in cases of the development of an acute respiratory distress syndrome (ARDS) (1).

In Italy, as of today, more than 150 thousand people have been infected, with an estimated fatality rate of $12.77 \%$ (2).

The healthcare professionals are widely exposed to the risk of contracting this virus; given its high infectivity, it is not surprising that they represent the $9 \%$ of all the infected individuals (2).

Moreover, dentists are also in extreme danger of acquire this disease; as direct transmission, since cough or sneeze or droplet transmission is the main way of spreading this disease, dental practitioners are exposed to high risk of contracting, and then spreading, COVID-19, due to their direct exposure to saliva and blood (3).

As a consequence, the most recommended guideline is that dentists should avoid scheduling any patient, and provide only emergencies during this outbreak; The Italian Ministry of Health has established that acute infections (such as an abscess), traumas and other forms of severe pain should be treated adopting several personal protection measures, such as wearing FFP-2 masks; despite of the short length of these appointments, the risk of contracting the disease still stands.

But if, after a short triage, the dentist suspects the patient might have contracted the virus, he should postpone the appointment and contact his general practitioner.

Another concern is that many patients must be quarantined as a means of stopping the outbreak or are admitted into a hospital. These patients might suffer from dental emergencies during their quarantine. Furthermore, many studies have demonstrated that oral health influence systemic diseases (4-15).

\section{MANAGEMENT OF NON-HOSPITALIZED PATIENTS}

Given the high probability that the SaRS-CoV-2 outbreak in Italy and in all countries might last for several months, more strict guidelines have to be defined in order to provide urgent care to bed-ridden or quarantined patients, in order to avoid an unexpected rise of severe odontogenic infections.

Our suggestion is to maintain an extremely high level of oral hygiene in these patients in order to avoid any emergencies; therefore they should wash their teeth at least 
twice a day, floss daily and use a $1 \%$ povidone-iodine mouthwash 3 to 4 times a day; this doesn't only reduce the risk of dental emergencies, but it also reduces the oral viral load and might, even if there is no evidence, reduce the risk of contaminating the surrounding environment.

This mouthwash could also be administered before any medical inspection to reduce the risk of healthcare professionals contracting the disease.

Still, if a dental emergency eventually develops, and the patient cannot see a dentist, we advise some solutions that can be offered as a temporary remedy.

If the discomfort comes from a third molar area or an abscess, we advise using an antibiotic therapy (Azithromicin $500 \mathrm{mg} 1$ per day for 3 days) and a mouthwash 3 times a day, as mentioned before, and applying a chlorhexidine gel twice a day over the area.

The same method can be used for diminishing the pain caused by third molar pericoronitis $(4,8,10)$.

Some emergencies in these patients can also be treated with some over the counter (OTC) products; if a cemented crown comes loose, the application of a temporary cement that can be easily found in a pharmacy, and that can be delivered to the patient's home, can avoid a trip to a dentist office, while at the same time diminishing the discomfort and avoiding the closure of the interocclusal and mesiodistal space.

Likewise, if a removable prosthesis causes heavy discomfort, the application of an OTC soft removable liner can temporarily allow the patient to maintain a healthy eating plan.

Clearly these procedures only remove some of the symptoms, but do not treat the disease; therefore, it is imperative to instruct patients to maintain high levels of oral hygiene, in order to prevent worsening of these conditions.

If the patient suffers from some symptoms that can be linked to an acute or chronic pulpitis, or some periapical disease, it can be administered an OTC pain reliever: the assumption of Acetaminophen, can temporarily reduce pain (16).

One should also remember that at the time being, according to the European Medicines Agency, there is no confirmed link between Ibuprofen and a worsening of Covid19. Therefore, NSAIDs should be used to control higher pain and swelling in patients that cannot receive proper dental care (17).

The difficult of seeing a dentist might lead to a higher number of Intensive Care Units patients admitted as a consequence of an odontogenic infection; a phenomenon that has notably intensified in the last years (17).

\section{MANAGEMENT OF HOSPITALIZED PATIENTS}

For intubated patients we recommend to adopt all the procedures needed for keeping high levels of oral hygiene; therefore, following what has been previously reported in the literature in an effort to avoid ventilatory assisted pneumonia (6), an operator should daily inspect the oral cavity, using a flashlight and a gauze to move soft tissues away, brushing their teeth using a single-use small toothbrush with a small amount of toothpaste and cleaning their dentures with the same toothbrush, and then applying some 1\% Povidone-lodine mouthwash with a gauze over all teeth surfaces, slowly massaging the gum (18).

This procedure can help to maintain a good oral hygiene and reduce oropharyngeal colonization (19).

This point should be stressed out, as it has been reported that the procedures for preserving oral health are not so well known among emergency care personnel (20), but they can prevent oral diseases and could prevent the spread of pathogenic microorganisms (21).

Applying these simple measures might severely reduce the number of patients that must receive dental treatment, therefore reducing the risk of transmission, and might help isolated people who suffer from acute conditions.

\section{CONCLUSION}

We must be aware of the high risk of COVID-19 infection in health workers, moreover in dentists. On the other hand, many people may currently need dental cures, and dental professional must have practical and easy to do protocols to avoid potential cross infections.

\section{REFERENCES}

1. Wang L, Wang Y, Ye D, Liu Q. A review of the 2019 Novel Coronavirus (COVID-19) based on current evidence. Int. J. Antimicrob. Agents 2020:105948. https://doi.org/10.1016/ j.ijantimicag.2020.105948 PMid:32201353

2. Santacroce L, Charitos IA, Del Prete R. COVID-19 in Italy: An Overview from the First Case to Date. Electron J Gen Med. 2020;17(6):em235. https://doi.org/10.29333/ejgm/7926

3. Cantore S., Ballini A. Coronavirus Disease 2019 (COVID-19) Pandemic Burst and Its Relevant Consequences in Dental Practice. Open Dent J 2020;14:111-112 https://doi.org/ 10.2174/1874210602014010111

4. Azzolino D, Passarelli PC, De Angelis P, Piccirillo GB, D'Addona A, Cesari M. Poor Oral Health as a Determinant of Malnutrition and Sarcopenia. Nutrients 2019;11:2898. https://doi.org/10.3390/nu11122898 PMid:31795351 PMCid:PMC6950386

5. Passarelli PC, Pasquantonio G, Manicone PF, Cerroni L, Condo' R, Mancini M, D'Addona A. Orofacial signs and dental abnormalities in patients with Mulvihill-Smith syndrome: A literature review on this rare progeroid pathology. Medicine (Baltimore) 2018;97:e0656. https://doi.org/10.1097/MD.0000000000010656

PMid:29718885 PMCid:PMC6392951

6. Bollero P, Passarelli PC, D’Addona A, Pasquantonio G, Mancini M, Condò R. Oral management of adult patients undergoing hematopoietic stem cell transplantation. Eur Rev Med Pharmacol Sci 2018;22:876-87. https://doi.org/ 10.26355/eurrev_201802_14365 PMid:29509233

7. Mangini F, Santacroce L, Bottalico L. [Periodontitis and systemic diseases]. Clin Ter. 2006 Nov-Dec;157(6):541-8. PMid:17228854

8. Passarelli PC, Lajolo C, Pasquantonio G, D’Amato G, Docimo R, Verdugo F, D'Addona A. Influence of mandibular third molar surgical extraction on the periodontal status of adjacent second molars. J Periodontol. 2019 Aug;90(8):84755. https://doi.org/10.1002/JPER.18-0415 PMid:30825324 
9. Bottalico L, Tatullo M, Marrelli M, Santacroce L. Lights and shadows of dental implants: focus on mucositis and perimplantitis and their biological markers. J Biol Regul Homeost Agents. 2016 Jul-Sep;30(3):859-61. PMid: 27655511

10. Passarelli PC, De Angelis P, Pasquantonio G, Manicone PF, Verdugo $F$, D'Addona A. Management of Single Uncomplicated Dental Extractions and Postoperative Bleeding Evaluation in Patients with Factor V Deficiency: A Local Antihemorrhagic Approach. J Oral Maxillofac Surg. 2018 Nov;76(11):2280-3. https://doi.org/10.1016/j.joms. 2018.06.022 PMid:30012405

11. Santacroce L, Cagiano R, Carlaio RG, Del Prete R, Bottalico L. [Dentistry oral hygiene and endocarditis. Pathophysiology and prophylactic therapy]. Recenti Prog Med. 2008 Oct;99(10):516-21. PMid:19040131

12. Santacroce L, Bottalico L, Mangini F. Dental hygiene procedure in a patient with Giardia lamblia infection. Int $J$ Dent Hyg. 2007 Aug;5(3):187-9. https://doi.org/10.1111/ j.1601-5037.2007.00240.x PMid:17615029

13. Passarelli PC, Pasquantonio G, D’Addona A. Management of Surgical Third Lower Molar Extraction and Postoperative Progress in Patients with Factor VII Deficiency: A Clinical Protocol and Focus on This Rare Pathologic Entity. J Oral Maxillofac Surg. 2017 Oct;75(10):2070.e1-2070.e4. https://doi.org/10.1016/j.joms.2017.06.010 PMid:28672139

14. Giudice G, Cutrignelli DA, Sportelli P, Limongelli L, Tempesta A, Gioia GD, Santacroce L, Maiorano E, Favia G. Rhinocerebral Mucormycosis with Orosinusal Involvement: Diagnostic and Surgical Treatment Guidelines. Endocr Metab Immune Disord Drug Targets. 2016;16(4):264-9. https://doi.org/10.2174/1871530316666161223145055 PMid:28017141

15. Santacroce L, Carlaio RG, Bottalico L. Does it make sense that diabetes is reciprocally associated with periodontal disease? Endocr Metab Immune Disord Drug Targets. 2010 Mar;10(1):57-70. https://doi.org/10.2174/187153010790827 975 PMid:20001897
16. Aminoshariae A, Kulild JC, Donaldson M, Hersh EV. Evidence-based recommendations for analgesic efficacy to treat pain of endodontic origin: A systematic review of randomized controlled trials. J. Am. Dent. Assoc. 1939 2016;147:826-39. https://doi.org/10.1016/j.adaj.2016.05. 010 PMid:27475974

17. Fu B, McGowan K, Sun H, Batstone M. Increasing Use of Intensive Care Unit for Odontogenic Infection Over One Decade: Incidence and Predictors. J. Oral Maxillofac. Surg. 2018;76:2340-7. https://doi.org/10.1016/j.joms.2018.05. 021 PMid:29958865

18. Koeman M, van der Ven AJAM, Hak E, Joore HCA, Kaasjager K, de Smet AGA, Ramsay G, Dormans TPJ, Aarts LPHJ, de Bel $E E$, et al. Oral decontamination with chlorhexidine reduces the incidence of ventilator-associated pneumonia. Am. J. Respir. Crit. Care Med. 2006;173:1348-55. https://doi.org/10.1164/rccm.200505-8200C PMid:16603609

19. Blot S, Vandijck D, Labeau S. Oral Care of Intubated Patients. Clin. Pulm. Med. 2008;15:153-60. https://doi.org/10.1097/CPM.0b013e3181729250

20. Bergmans DC, Bonten MJ, Gaillard CA, Paling JC, van der Geest S, van Tiel FH, Beysens AJ, de Leeuw PW, Stobberingh EE. Prevention of ventilator-associated pneumonia by oral decontamination: a prospective, randomized, doubleblind, placebo-controlled study. Am. J. Respir. Crit. Care Med. 2001;164:382-8. https://doi.org/10.1164/ajrccm.164. 3.2005003 PMid:11500337

21. Feider LL, Mitchell P, Bridges E. Oral care practices for orally intubated critically ill adults. Am. J. Crit. Care Off. Publ. Am. Assoc. Crit.-Care Nurses 2010;19:175-83. https://doi.org/ 10.4037/ajcc2010816 PMid:20194614

22. da Silva JL, de OEI Kadre GD, Kudo GA, Santiago JF, Saraiva PP. Oral Health of Patients Hospitalized in the Intensive Care Unit. J. Contemp. Dent. Pract. 2016;17:125-9. https://doi.org/10.5005/jp-journals-10024-1814 PMid:27207000 